\title{
Usage of Human Resource Information System and Its Application in Business: A Study on Banking Industry in Bangladesh
}

\author{
Faruk Bhuiyan', Mohammad Osman Gani² \\ ${ }^{1}$ Department of Business Administration, International Islamic University Chittagong, Chittagong, Bangladesh \\ ${ }^{2}$ Department of Marketing, Faculty of Business Studies, Bangladesh University of Professionals, Dhaka, \\ Bangladesh \\ Email: farukbhn84@gmail.com, osman@bup.edu.bd
}

Received 17 July 2015; accepted 12 September; published 15 September 2015

Copyright @ 2015 by authors and Scientific Research Publishing Inc.

This work is licensed under the Creative Commons Attribution International License (CC BY).

http://creativecommons.org/licenses/by/4.0/

(c) (i) Open Access

\section{Abstract}

The study aimed at examining the perceived importance of human resource information system (HRIS) in business. A structured questionnaire was used to get an opinion from human resource end-users from the 55 scheduled banks consisted of 8427 branches. A total of 1200 responses were returned as the complete form. The study then extracted the perceived important reasons of using HRIS in business through principal component (PCA) analysis. In addition, one-way analysis of variance (ANOVA) was tested to examine the variance levels among the responses. The results of the existing study revealed that HRIS only automates the repetitive HR functions but also facilitates HR end-users in allocating workforces effectively, promoting suitable corporate culture, designing employees' career plan and improving services to the employees. Further, it found no significant variances among HR end-users' responses on the perceived importance of HRIS according to their demographic variables. Albeit many studies had been conducted on the importance of HRIS, there was hardly any study that had gone through factor analysis. However, this study provided broad evidence to enrich the existing literature in the respective field, with improved methodological and measurement issues including factor analysis over the previous studies, to unleash the importance of HRIS in business.

\section{Keywords}

Human Resource Information System, Human Resource End-Users, Usage, Factor Analysis, Banking Industry 


\section{Introduction}

Human resources are undoubtedly the most significant resources in the organization regardless of size (number of employees), volume of capital, nature of operation, objective, ownership pattern, country, and emerging period. On the other hand, information and communication technology (ICT) has been contributed a vital role in the success of today's organizations [1] since 18th century [2]. Like the other functional departments of the organization, human resource (HR) division has also come under the privileges of ICT. Nowadays, most of the HR functions are executed with the help of information technology (IT) [3]. Though the functions of HRM have been automated after the other functional areas, it does not mean that it is less important to the organization. HR division has been lately automated due to its inherent functional complexity and volume. Where human resource information system (HRIS) allows HR-end users: HR professionals, functional level managers and employees to collect, store, maintain, analyze and disseminate the pertinent information regarding HR policies, functions and strategies intended for ensuring and securing firms' consistent performance. Many researchers in this field agree on its wide variety of uses including better internal communication [4], knowledge sharing, employee self-services, real time information sharing, easy and quick access to the accurate information [5] [6], while its application is at early stage in Bangladesh. Albeit researchers identify several benefits of this technology in performing HR functions [7]-[9], any empirical research with factor analysis is rare investigate its true importance in organizations. Similarly, methodologically and theoretically sound researches are also insufficient to this field. As banking industry of Bangladesh is intensely competitive in nature, it is the HR end-users' demand to understand the true benefits of HRIS so that they can make suitable policies and deploy resources accordingly on the different aspects of HRIS. Moreover, the impact of technological revolution in the area of HRM seems to be lagging behind in the research field [10]. However, to contribute in the field of HRIS, this study directs to empirically examine the perceived importance of HR technology to perform HRM activities in the banking industry of Bangladesh. Hence, specific endeavors of the study are directed:

- To review the importance of IT on HRM activities;

- To extract the relevant perceived importance of HRIS and finally;

- To examine whether the importance of HRIS differs to the HR end-users according to their demographic variables.

To materialize the specific objectives, the author first extensively reviews the available empirical findings regarding the importance of IT to HRM. The study then develops three hypotheses relating to the perceived differences of the respondents' opinion on the importance of HRIS in respect to their demographic characteristics. After that, it describes the methodological part in detailed including the measurement development through principal component factor analysis with direct Oblimin rotation method. This paper next abridges the main findings based on the survey results and theoretical discussions regarding the perceived significance HRIS. Finally, it concludes with some policy recommendations for future research on this IT supportive HR technology.

\section{Prior Empirical Work}

With the proved benefits of IT in the business, HRIS applications facilitate the multi-faced functional areas of HRM. The facilitating features of HRIS have here been shown by extracting gist from the extensive literature published in the referred journals in multiple years.

\subsection{Automate the Repetitive Administrative Functions}

Almost all HR processes can be done by using HRIS on a daily basis which facilitates the organization in several ways, like; automate the business and its processes, reduce the use of resources, such as; financial, material and human [11]. Burbach and Dundon [12] conducted a study on the strategic potential of HRIS on 520 organizations in the Republic of Ireland. They argued that HRIS mostly uses for better performing the administrative functions of HR department rather than strategic purposes. Similar results also found from a study on the impact of e-HR on HRM functions [13]. In addition, Hendrickson [14] argued that HRIS facilitates by providing employee self-service facility to increase its efficiency and effectiveness Further, another study on the impact of information systems on the performance of HR department conducted by Sadiq, U., Khan, A. F. \& Ikhlaq K. [15] in 2012 on 18 HR managers from the various corporations operating in Lahore, Pakistan and suggested that HRIS can be positively used as a tool to achieve greater administrative efficiency by adding values in the department. Finally, Chugh [16] mentioned that HRIS reduced workload by minimizing repetitive administrative 
tasks as one of the main benefits of this technology.

\subsection{Improve Service to Employees}

HRIS enabled employees to perform their HR related activities independently at any time and place. For instance, the self-service application of HRIS allows managers to upload immediately the performance assessment results while employees can manage their performance goals and make performance plan on their personal page [17]. Moreover, this application allows them to take on or confirm of their benefit claims and lastly transfer request in real time. As a result managers are being informed about employee choice that they need to make or verify about rewards of their subordinates and finally ask them to insert their decision.

\subsection{Help Managers Stay Informed}

Recent developed of IT in the area of HR enables managers to stay informed with real time pertinent information for taking strategic decisions [13]. For instance, a study conducted by Sharyn et al. [18] on virtual HR: the impact of information technology on the human resource professional, suggested to HR professionals to use IT in HRM functions that enables them to more efficiently access and disseminate relevant information.

\subsection{Improved Communication}

HRIS links to the faster information processing, greater information accuracy, improve planning, and program development and enhance employee communication [18]. Kovach et al. [19] conducted a study on providing business with rapid data access, information exchange and strategic advantage. They pointed out that HRIS gathers information faster at lower costs that required maintaining internal relation among employees and employers. Further, another study conducted by Batool et al. [4] on benefits and barriers of HRIS in accounts office. They found that HRIS allows HR people to access quickly to information and response on time.

\subsection{Allocate Workforce More Effectively}

Bal et al. [20] mentioned in their study on the importance of HRIS application on determining the success that HRIS supports several HR activities including identifying potential employees, maintaining complete records on existing employees, creating program to develop employee talents and skill, identifying manpower requirement and placement of the employee.

\subsection{Employee Career Design}

Among IT supportive functions of HRM, training and development aspect is mostly performed at cost effective way. The internet technology can be used in performing training need assessment in e-learning activity and career management [20]. The use of technology in the area of HRM often leads to new horizon of collaborating, organizing work, building teams and developing new knowledge and skills. And this can help further to build organizational and human capital.

From the above discussion on the prior empirical studies, it has been seen that IT plays significant roles in the different aspects of HRM that lead to reduce repetitive administrative roles of HR unit, facilitate managers be well informed, improve internal communication, allow employee self-service, effectively allocate workforce and finally help in employee career design.

\section{Limitations of the Prior Empirical Work}

IT has been seen from the prior empirical works have consistently found that HRIS has more potential to its end-users. However, if we step forward on this line of research, some serious limitations in the prior empirical works have to be addressed. Four are methodological issues while one is conceptual and measurement. First, most of the previous researches based on the small sample size which leads down the chance to detect true relationships of IT in HRM. Second, some of the studies were characterized by common method bias as these studies conducted based on the information acquired from single respondent of each organization. Third, survey respondents, most of the cases, self-selected that influenced the survey results. Fourth, many studies limited to one specific country only that hampered to generalize the findings. Finally, most of the previous empirical stu- 
dies based on only one or two or a few aspects of HRIS to the HR unit. In this junction, a comprehensive study on the perceived benefits of HRIS to the HR end-users, with large sample size consists of more than one respondents selected randomly from each organization, may add knowledge in this field.

\section{Hypothesis Development}

With the prior empirical studies and our principle component factor analysis (detailed discussion at measurement development part) for extracting the related factors on the importance of HRIS to the HR end-users, author put forward hypotheses to examine whether there are significant differences in respondents' opinion, depending on their age, educational background and service length, on the importance of HRIS in the organization. For the study purpose, the respondents were categorized into five different age groups (detailed in the methodological part). Since, the concept of HRIS is the recent revolution in the business phenomena, the perceptions to the relative importance of HRIS application may differ. As older employees are less attached with the internet technology than younger employees, they are mostly reluctant to adopt new technology for a fear of losing the job due to their inability to cope with the technology. The study, therefore, assumes the following hypothesis H1.

H1: The perceived importance of HRIS to the HR end-users varies according to the age of respondents.

Though banking industry in Bangladesh is characterized by comparatively higher educated employees, the study here categorizes the respondents into five different educational backgrounds (detailed in the methodological part) started from higher secondary up to PhD degree. To understand the true benefits of IT on HRM, HR professionals require sound computer literacy and competence on HRIS. According to Teo et al. [21], a slow rate of IT application is a result of lack of HRIS knowledge and skills. Moreover, people having comparatively higher education can quickly and easily cope with the internet technology [22]. Hence, the author hypothesizes the following hypothesis, $\mathrm{H} 2$.

H2: The perceived importance of HRIS to the HR end-users varies according to the educational background of the respondents.

Employees with more job experience have comparatively sound knowledge in the different business aspects. They know better about the future need of the business. In the intensely competitive market environment, long term survival is under threat. In this situation, experienced personnel may able to better forecast about demands. As a result, author categorizes the study respondents into five different groups (detailed in the methodological part) based on the length of job experiences. The study, therefore, assumes the following statement as hypothesis H3.

H3: The perceived importance of HRIS to the HR end-users varies according to the length of job experiences of the respondents.

\section{Methods}

\subsection{Sample}

The study considers survey based research to examine the importance of HRIS to the HR end-users in the banking industry of Bangladesh. It selects banking industry from Bangladesh as a blood circulating for all sectors of business because it has consistently been contributed significant amount to the country's GDP since 1972. This industry consists of 55 scheduled banks (listed in Bangladesh Bank, Central bank of Bangladesh) including 8427 branches [23].

\subsection{Data Gathering Instrument}

A structured questionnaire, consists of 10 questions related to the perceived importance of HRIS application extracted from the prior studies, was designed for the survey purpose. The probable responses were constructed based on 5-point Likert scale stated 1 for "not important at all” and 5 for "highly important".

\subsection{Respondents}

As the designation of concerned HR authority varies from firm to firm, a structure questionnaire was mailed to the HR practitioners, managers, directors, assistant director, and officers of the firms. An employee from each bank (non-respondent) was assigned to monitor the progress of filling questionnaires. Total 1200 responses 
came back in complete form from them which accounts for the response rate of 56 percent. Out of 1200 respondents, $6.7 \%$ were under the age group of 25 - 29 years, 32.1\% came from the age group of 30 - 34 years, 51.1\% of them were between 35 - 39 years old, $5.7 \%$ of them came from the age group of 40 - 49 years, and finally $1.5 \%$ of the respondents had more than 49 years. On the other hand, $9 \%$ of the respondents completed degree certificate, $12.6 \%$ of them had bachelor degree, $67.3 \%$ of them obtained mater degree, and finally $8.2 \%$ of the respondents had either M.Phil or PhD degree. Finally, 4.8\%, 36.1\%, 45.3\%, 13.4\% and $0.3 \%$ of total respondents have less than 5, 5 - 9, 10 - 14, 15 - 24 and above 24 years of job experiences respectively. Hence, most of the respondents (95.2\%) have more than 5 years of experiences.

\subsection{Measurement of Perceived Benefits of HRIS}

Factor identification: from the very beginning of the emergence of the concept of HRIS in the field of HRM, several works have been done to identify why HR peoples use HRIS in performing their HR activities effectively and efficiently. Unfortunately, most of them were limited to the mere identification of important reasons behind choosing HRIS by using descriptive statistical tools. Therefore, it is insufficient to get the more general idea about its importance. Here, the study analyzes the factors extracted from the prior published research works to identify the closely related factors by applying Principle Component Factor Analysis. The study has chosen ten most frequently stated benefits of HRIS applications: help manager stay informed, allocate workforce more effectively and efficiently, automate the repetitive functions of HR department, promote corporate culture, help in designing employee's career plan, allow better communication between management and employees, update employee knowledge with the required information, accelerate knowledge sharing among the different users, improve services to the employees, enhance communication among employees. Responses from 1200 respondents have gathered to identify the common perceived benefits of HRIS factors and Principal Component Analysis (PCA) has been considered in this regard.

From the correlation matrix, it has been seen that some of the items have score more than 0.3 and hence it is appropriate for factor analysis [24]. In addition, two statistical measures are also tested to assess the factorability of the data. According to Kaiser-Meyer-Olkin (KMO) measure of sampling adequacy index should be more than 0.6 [25] and Bartlett's test of sphericity should be less than 0.05 [26]. KMO ratio and Bartlett test of sphericity of the sample responses are 0.637 and 0.000 respectively (insert Table 1). Hence, these data are suitable for factor analysis. So, the study goes for factor analysis.

To determine optimum number of factors (components) for the study will extract, author has tested four different options. Kaiser's criterion, as one the four options, suggests to extract the factors with eigenvalue of 1 or more. The PCA shows that there are 4 factors consist of eigenvalues more than $1(2.149,1.283,1.136$, and 1.068). These four factors explain the 56 percent of variance (see cumulative percentage column in total variance explained Table 2).

Similarly, Scree Plot is another option that can facilitate researchers to extract the right factors for the further study. From the Scree Plot, it has been seen that 3 factors exist above the second elbow but below the first elbow. This indicates to extract three factors for further consideration. Since there is a mismatch between the findings of two extraction options, the study further considers Parallel analysis as a third way of determining the number of factors retained. The output from parallel analysis of 10 variables, and 1200 subjects with 100 replications are given in Table 3.

The study at this stage goes for comparison of eigenvalues from PCA and criterion values from parallel analysis. Components having eigenvalue higher than the criterion value should be retained. The summary of the comparisons is shown in Table 4.

Hence, the parallel analysis suggests four components to retain. The final option, Component Matrix, needs to look at this stage. The un-rotated loadings table shows of each of the items on the four components presented in

Table 1. Kaiser-meyer-olkin measure of sampling adequacy index and bartlett's test of sphericity.

\begin{tabular}{lcc}
\hline \multicolumn{2}{c}{ Kaiser-Meyer-Olkin Measure of Sampling Adequacy } & 0.637 \\
& Approx. Chi-Square & 1037.850 \\
Bartlett's Test of Sphericity & Df. & 45 \\
& Sig. & 0.000 \\
\hline
\end{tabular}


Table 2. Total variance explained.

\begin{tabular}{cccccccc}
\hline \multirow{2}{*}{ Component } & \multicolumn{3}{c}{ Initial Eigenvalues } & \multicolumn{2}{c}{ Extraction Sums of Squared Loadings } & \multicolumn{2}{c}{ Rotation Sums of Squared Loadings ${ }^{\mathrm{a}}$} \\
\cline { 2 - 7 } & Total & \% of Variance & Cumulative \% & Total & \% of Variance & Cumulative \% & Total \\
\hline 1 & 2.149 & 21.491 & 21.491 & 2.149 & 21.491 & 21.491 & 2.128 \\
3 & 1.283 & 12.834 & 34.325 & 1.283 & 12.834 & 34.325 & \\
4 & 1.136 & 11.360 & 45.685 & & & & \\
5 & 1.068 & 10.677 & 56.362 & & & & \\
6 & 0.999 & 9.989 & 66.351 & & & & \\
7 & 0.828 & 8.276 & 74.628 & & & & \\
8 & 0.775 & 7.750 & 82.378 & & & & \\
9 & 0.695 & 6.955 & 89.333 & & & & \\
10 & 0.589 & 5.887 & 95.220 & & & & \\
\end{tabular}

Extraction Method: Principal Component Analysis. ${ }^{\mathrm{a}}$ When components are correlated, sums of squared loadings cannot be added to obtain a total variance.

Table 3. Output from parallel analysis. 7/16/2014 2:56:06 PM. number of variables: 10; number of subjects: 1200; number of replications: 100.

\begin{tabular}{ccc}
\hline Eigenvalue & Random Eigenvalue & Standard Deviation \\
\hline 1 & 1.1418 & 0.0222 \\
2 & 1.1018 & 0.0178 \\
3 & 1.0680 & 0.0140 \\
4 & 1.0410 & 0.0116 \\
5 & 1.0118 & 0.0118 \\
6 & 0.9864 & 0.0120 \\
7 & 0.9586 & 0.0131 \\
8 & 0.9305 & 0.0131 \\
9 & 0.8996 & 0.0144 \\
10 & 0.8606 & 0.0177 \\
\hline
\end{tabular}

Monte Carlo PCA for Parallel Analysis (C) 2000 by Marley W. Watkins. All rights reserved.

Table 4. Comparison of eigenvalues from PCA and criterion values from parallel analysis.

\begin{tabular}{cccc}
\hline Component Number & Actual Eigenvalue from PCA & Criterion Values from Parallel Analysis. & Decision \\
\hline 1 & 2.149 & 1.1418 & Accepted \\
2 & 1.283 & 1.1018 & Accepted \\
3 & 1.136 & 1.0680 & Accepted \\
4 & 1.068 & 1.0410 & Accepted \\
5 & 0.999 & 1.0118 & Rejected \\
6 & 0.828 & 0.9864 & Rejected \\
7 & 0.775 & 0.9586 & Rejected \\
\hline
\end{tabular}

the component matrix table. From the component matrix it has been seen that most of the items loaded strongly on the first two components. Very few items load on the components 3 and 4. Therefore, it suggests that two-factor solution is likely to be more appropriate. Hence, the study now goes for two-factor solution to take final decisions on the components to be retained.

From the total variance explained table, it has been seen that two-factor solution explains total 34.325 percent 
(21.491\% and $12.834 \%)$ of the variance compared to total 56.362 percent variance explained by four-factor solution. In addition, to interpret two components elaborately, Oblimin rotation was performed which is given in the pattern matrix Table 5 .

The component correlation matrix (insert Table 6) shows the strength of correlation between two components that is estimated 0.006 in this study. Since, the correlation between two components is more less than 0.2 indicates a very week correlation between them. Moreover, they are almost independent from or no relation to each other. Hence the decision of Oblimin's two-factor solution is appropriate for the study.

From the pattern matrix, it has been seen that component-1 loads five variables with high scores of more than 0.4 each: allocate workforce more effectively and efficiently, promote corporate culture, help in designing employee's career plan, automate the repetitive functions of HR department, and improve services to the employees. On the other hand, component-2 loads 3 variables: update employee knowledge with the required information, accelerate knowledge sharing among the different users, and enhance communication among employees. Therefore, from the PCA, the study finds two broad components consist of many variables. Two major components with their highest factor loadings are shown in Table 7.

Table 5. Pattern matrix .

\begin{tabular}{|c|c|c|}
\hline & \multicolumn{2}{|c|}{ Component } \\
\hline & 1 & 2 \\
\hline Allocate workforce more effectively and efficiently & 0.746 & \\
\hline Promote corporate culture & 0.648 & \\
\hline Help in designing employee’s career plan & 0.602 & 0.368 \\
\hline Help manager stay informed & -0.568 & \\
\hline Automate the repetitive functions of HR department & 0.492 & \\
\hline Improve services to the employees & 0.407 & \\
\hline Update employee knowledge with the required information & & 0.646 \\
\hline Accelerate knowledge sharing among the different users & & 0.555 \\
\hline Allow better communication between mgt. and employees & & -0.421 \\
\hline Enhance communication among employees & & 0.322 \\
\hline
\end{tabular}

Extraction Method: Principal Component Analysis. Rotation Method: Oblimin with Kaiser Normalization. ${ }^{\mathrm{a}}$ Rotation converged in 6 iterations.

Table 6. Component correlation matrix.

\begin{tabular}{cccc}
\hline Component & 1 & 2 \\
\hline 1 & 1.000 & 0.006 \\
2 & 0.006 & 1.000 \\
\hline
\end{tabular}

Extraction Method: Principal Component Analysis. Rotation Method: Oblimin with Kaiser Normalization.

Table 7. Components' variables with the highest score loadings.

\begin{tabular}{|ccc|}
\hline Item & 1 & 2 \\
\hline Facilitating HR activities & 0.746 & 0.200 \\
\hline Allocate workforce more effectively and efficiently & 0.648 & 0.138 \\
Promote corporate culture & 0.602 & 0.368 \\
Help in designing employee's career plan & 0.492 & -0.067 \\
Automate the repetitive functions of HR department & 0.407 & -0.193 \\
\hline Improve services to the employees & 0.746 & 0.200 \\
\hline Improve communication & & 0.646 \\
\hline Update employee knowledge & -0.165 & 0.555 \\
\hline Accelerate knowledge sharing & -0.080 & 0.322 \\
\hline
\end{tabular}




\subsection{Reliability and Validity Testing}

To use the scales (those are extracted from PCA) for further study, author tests internal consistency of component variables by calculating Cronbach's Alpha. Test scores are given in Table 8. According to Sekeran, U. [27] scale with Cronbach's Alpha test score less than 0.6 is poor, between 0.6 to 0.8 is considered acceptable and above 0.8 indicates good for further study. In this study we see Cronbach's Alpha for the component- 1 (facilitating HR activities) is 0.606 which persuade the author to consider the component for the study purpose. But the test score for the component-2 (improved communication) is 0.088 which indicates poorly considerable factor for further study.

On the other hand, a study conducted by Ngai et al. [28] to investigate the perceptions of HR practitioners regarding the importance of internet in HRM activities based on the 147 respondents from selected public companies quoted on the Hong Kong Stock Exchange. They asked the respondents to rate out of nine important reasons. Among the nine reasons, they found six statistically significant: help managers stay informed, allow better communication between management and employees, reduce costs in the long run, improve services to the employees, enhance communication among employees, allocate workforce more effectively and efficiently. Based on the responses, they found "help managers stay informed, which occupied the highest mean score of 3.83", as most important reason for an organization to adopt internet for HRM. However, the study considers ten reasons including six reasons found from the study of Ngai et al. [28] for further analysis through PCA with direct Oblimin rotation method. From PCA, the study finds 5 (out of 10) related important reasons to the application of HRIS in organizations: allocate workforce more effectively and efficiently, promote corporate culture, help in designing employee's career plan, automate the repetitive functions of HR department, and improve services to the employees.

\section{Results}

To test the hypotheses, the study deploys one-way analysis of variance (ANOVA), to examine any mean difference in the respondents' perceptions of why they deal with HRIS in respect to different age groups, educational backgrounds and service length. The measurement for the relative degree of perceptions as a reason was set on the five point rating scale: from not important at all (1) to the most important (5). Moreover, a variable with the mean value significantly larger than 3 (three) is regarded as an important reason.

Hypothesis-1: One-way ANOVA table (insert Table 9) on the perceived benefits (except "help in designing employee career plan") of IT in HRM according to the age groups found no significant F-value $(p \leq 0.05)$. Moreover, the results of testing $\mathrm{H} 1$ reveal no significant difference of responses on the perceived importance of HRIS applications according to the respondents' age levels. Table also shows the summary of sample mean ratings of the measurements. Total 4 reasons: allocate workforce more effectively and efficiently, promote corpo-

Table 8. Factors with cranach's alpha scores.

\begin{tabular}{|c|c|c|c|}
\hline Item & 1 & 2 & Alpha \\
\hline Facilitate HR activities & & & 0.606 \\
\hline Allocate workforce more effectively and efficiently & 0.746 & 0.200 & \\
\hline Promote corporate culture & 0.648 & 0.138 & \\
\hline Help in designing employee’s career plan & 0.602 & 0.368 & \\
\hline Automate the repetitive functions of HR department & 0.492 & -0.067 & \\
\hline Improve services to the employees & 0.407 & -0.193 & \\
\hline Help manager stay informed ${ }^{\mathrm{a}}$ & -0.568 & 0.249 & \\
\hline Improved communication & & & 0.088 \\
\hline Update employee knowledge & -0.165 & 0.646 & \\
\hline Accelerate knowledge sharing among the different users & -0.080 & 0.555 & \\
\hline Enhance communication among employees & 0.028 & 0.322 & \\
\hline Allow better communication ${ }^{\mathrm{a}}$ & -0.144 & -0.421 & \\
\hline
\end{tabular}

\footnotetext{
${ }^{\mathrm{a}}$ Items have reversed coded.
} 
rate culture, automate the repetitive functions of HR department, and improve services to the employees have mean values significantly larger than 3 (three). Based on the responses, it seems that the most important reason of implementing HRIS is to automate the repetitive HR functions which accounts for the highest mean score of 4.19. In case of the variable "help in designing employee career plan", F-value is significant at $0.038(p \leq 0.05)$ which refers to the difference of responses on the variable "help in designing employee career plan" among the different age groups. Moreover, HR end-users with different age levels have various weights on the application of HRIS in designing employee career plan.

Hypothesis-2: Table 10 summarizes the results obtained from the output of one-way ANOVA. No significant F-values $(p \leq 0.05)$ have found on the four variables: promote corporate culture, help in designing employee's career plan, automate the repetitive functions of HR department, and improve services to the employees. Moreover, the results of testing $\mathrm{H} 2$ revealed that there is no significant difference between perceptions of HR endusers and their education backgrounds to the importance of HRIS applications. A variable with the mean value significantly larger than 3 (three) is regarded as an important reason. Overall 4 reasons have mean values significantly larger than three. Based on the survey, it seems that the most important reason to the implementation of HRIS is that it automates the repetitive functions of HR department having the highest mean score (4.19). In case of the variable "allocate workforce effectively and efficiently" we found significant F-value $(p \leq 0.05)$ which indicates a significant difference on the respondents of the different educational background regarding the variable "allocate workforce effectively and efficiently".

Hypothesis-3: The study finally forwards to the test of hypothesis-3 which is based on the results found from one-way ANOVA. The summary of results is shown in Table 11. The variable, allocate workforce more effectively and efficiently, does not consider for further analysis because it violates the assumption of homogeneity of variance as its significance value (.000) for Levene's test is less than 0.05 (Table 11).

Results show no significant F-values on the perceived benefits of HRIS application $(p \leq 0.05)$ according to service lengths: promote corporate culture, automate the repetitive functions of HR department and improve

Table 9. Significant differences according to respondents’ age levels.

\begin{tabular}{|c|c|c|c|c|c|c|c|c|c|c|c|c|c|c|}
\hline \multirow{2}{*}{ Reasons } & \multicolumn{2}{|c|}{ Whole sample } & \multicolumn{2}{|c|}{25 - 29 yrs. } & \multicolumn{2}{|c|}{$30-34$} & \multicolumn{2}{|c|}{$35-39$} & \multicolumn{2}{|c|}{$40-49$} & \multicolumn{2}{|c|}{ Above 49 yrs. } & \multirow{2}{*}{ F-Value } & \multirow{2}{*}{ Sig. } \\
\hline & Mean & SD & Mean & SD & Mean & SD & Mean & SD & Mean & SD & Mean & $\mathrm{SD}$ & & \\
\hline $\mathrm{F}-2$ & 4.16 & 0.613 & 4.11 & 0.583 & 4.14 & 0.666 & 4.15 & 0.605 & 4.17 & 0.616 & 4.18 & 0.628 & 0.160 & 0.959 \\
\hline F-8 & 3.65 & 1.160 & 3.83 & 1.043 & 3.63 & 1.066 & 3.61 & 1.183 & 3.68 & 1.166 & 3.82 & 1.049 & 0.776 & 0.547 \\
\hline F-7 & 4.14 & 0.776 & 4.33 & 0.594 & 4.23 & 0.745 & 4.11 & 0.761 & 4.16 & 0.773 & 4.17 & 0.824 & 0.899 & 0.464 \\
\hline F-9 & 4.19 & 0.681 & 4.22 & 0.647 & 4.27 & 0.679 & 4.18 & 0.689 & 4.17 & 0.684 & 4.29 & 0.615 & 0.884 & 0.473 \\
\hline F-10 & 4.05 & 0.805 & 4.17 & 0.707 & 4.06 & 0.759 & 4.02 & 0.793 & 4.04 & 0.841 & 4.31 & 0.748 & 2.542 & 0.038 \\
\hline
\end{tabular}

Table 10. Significant differences according to respondents' educational backgrounds from one-way ANOVA test.

\begin{tabular}{|c|c|c|c|c|c|c|c|c|c|c|c|}
\hline \multicolumn{2}{|c|}{ Whole Sample } & \multicolumn{2}{|c|}{ Education } & \multicolumn{2}{|c|}{ Bachelor } & \multicolumn{2}{|c|}{ Masters } & \multicolumn{2}{|c|}{ M.Phil. \& PhD } & \multirow{2}{*}{ F-Value } & \multirow{2}{*}{ Sig. } \\
\hline Mean & SD & Mean & SD & Mean & SD & Mean & SD & Mean & SD & & \\
\hline 4.16 & 0.613 & 4.19 & 0.595 & 4.16 & 0.626 & 4.12 & 0.583 & 4.19 & 0.596 & 0.362 & 0.780 \\
\hline 3.65 & 1.160 & 3.17 & 1.233 & 3.70 & 1.151 & 3.82 & 1.044 & 3.54 & 1.212 & 7.818 & 0.000 \\
\hline 4.14 & 0.776 & 4.11 & 0.677 & 4.17 & 0.753 & 4.12 & 0.830 & 3.98 & 0.831 & 2.107 & 0.098 \\
\hline 4.19 & 0.681 & 4.21 & 0.712 & 4.18 & 0.695 & 4.20 & 0.627 & 4.17 & 0.631 & 0.073 & 0.975 \\
\hline 4.05 & 0.805 & 3.97 & 0.780 & 4.06 & 0.821 & 4.10 & 0.738 & 3.96 & 0.797 & 1.065 & 0.363 \\
\hline
\end{tabular}

Table 11. Levene's test of homogeneity of variances.

\begin{tabular}{ccccc}
\hline & Levene's Statistic & df1 & df2 & Sig. \\
\hline Improve services to the employees & 0.706 & 4 & 1195 & 0.588 \\
Allocate workforce more effectively and efficiently & 5.113 & 4 & 1195 & 0.000 \\
Promote corporate culture & 1.647 & 4 & 1195 & 0.160 \\
Automate the repetitive functions of HR dept. & 1.737 & 4 & 1195 & 0.139 \\
Help in designing employee's career plan & 0.709 & 4 & 1195 & 0.586 \\
\hline
\end{tabular}


services to the employees. Moreover, the results of testing H3 reveal no significant difference on the perceptions of HR end-users characterized by different service lengths regarding the importance of HRIS applications. In case of the variable "help in designing employee career plan", the study found significant F-value, 0.023 ( $p \leq$ 0.05). It indicates significant difference among the respondents' responses, having different educational backgrounds, on helping in designing employee career plan. In addition, the table also shows the summary of sample mean ratings of the measurements.

\section{Discussion}

Though prior works in both academic and research experiments on perceived importance of HRIS applications to business is enormous, any work is hardly found that dealt with factor analysis on the perceived importance of HRIS. However, this study provides broad evidence in support of this contention. From the survey, author found two broad factors of the application of HRIS: facilitating HR activities and improved communication. The first factor consists of five variables why HR end-users perceived to deploy IT in HRM: allocate workforce more effectively and efficiently, promote corporate culture, help in designing employee's career plan, automate the repetitive functions of HR department, and improve services to the employees. On the other hand, the second factor consists of 3 closely related variables: Update employee knowledge with the required information, accelerate knowledge sharing among the different users and enhance communication among employees. Cronbach's Alpha scores of these two factors are 0.606 and 0.088 respectively. Here, factor- 1 goes for further analysis while factor-2 is ignored from the further analysis. Therefore, the perceived importance of HRIS application is to facilitate the HR end-users in allocating workforces effectively and efficiently, promoting corporate culture, assisting in designing suitable employees' career plan, reducing repetitive HR functions and improving services to the employees.

The study then forwards to test hypotheses based on the five variables through one-way analysis of variance (ANOVA). The results of testing H1 reveal that there is no significant difference between the perceptions of HR end-users and age groups regarding the importance of HRIS applications except the variable-help in designing employee career plan. Further, it seems that the most important reason of implementing HRIS in organization is it automates the repetitive functions of HR department as it occupies having the highest mean score (4.19). However, the survey found a significant difference on the responses from different age groups on "help in designing employee career plan”.

The results of testing $\mathrm{H} 2$ expose that there is no significant difference between perceptions of HR end-users, with diverse educational backgrounds, on the importance of HRIS applications. It also seems that the most important reason to the implementation of HRIS is that it automates the repetitive functions of HR department as it consists of the highest mean score of 4.19. On the contrary, the study found a significant difference of the responses from HR end-users profiled distinctive educational levels on the variable of "allocate workforce effectively and efficiently". Moreover, HR end-users have mostly identical perceptions upon corporate culture, career design, repetitive HR functions and employee self-service as the benefits of the application of HRIS in business organization.

Finally, the results of testing $\mathrm{H} 3$ divulge that there is no significant difference on the perceptions of HR end-users, with various service lengths, on the importance of HRIS in business: improve services to the employees, promote corporate culture, and automate the repetitive functions of HR department. However, it further reveals that respondents having ages among 25 - 29, 30 - 34 and 35 - 39 differ significantly in term of HRIS helps in designing employee career scores.

Moreover, the uses of IT in the field of HRM are diverse. HR-end users are unanimously agreed upon the perceived benefits of HRIS in the organization regardless of their age, educational background and service length. HRIS helps HR unit to allocate workforce more effectively and efficiently, promote corporate culture, designing employee's career plan, automate the repetitive functions of HR department, and improve services to the employees. Hence, HR end-users will be benefited from the findings of the existing comprehensive study to realize truly about the importance of implementing HRIS in organizations under the intense competitive market environment.

\section{Concluding Remarks}

Information and communication technology have undoubtedly brought revolutionary changes into business. 
Most of the functional departments of an organization have already adopted this technology to ensure their departmental performance at expected level. Similarly, HRIS has now-a-days brought the drastic changes in functioning of HR activities. Today's HR people are more aware about the potentiality of HRIS applications in the organizations. As most of the previous HRIS related studies are methodologically and conceptually criticized, the need for further studies on the same issue has emerged. Hence, the existing study unleashes the survey results on the perceived benefits of HRIS in organizations. The study finds five stimuli: allocate workforce more effectively and efficiently, promote corporate culture, help in designing employee's career plan, automate the repetitive functions of HR department, and improve services to the employees for HR end-users to come forward in implementing this technology for smooth performing of HR activities in an efficient way. The study results come to a very close to what Ngai et al. [28] found in their study. As IT may be used to perform the repetitive functions of traditional HR, HRIS may be a good option to replace those repetitive HR functions. Among the enormous positive wings of HR technology, most of the respondents (irrespective of ages, educational backgrounds, and service lengths variations) are highly agreed (mean value of 4.15) upon the stated benefits of HRIS which automates the repetitive and boring functions of traditional HRM. In addition, as internet technology allows HR managers to keep the employee profile's information permanently with the greater accuracy and high visibility, any modification or alteration taken into account to the employee profile can be easily performed without any kind of delay. Almost all of the clerical functions of HR department can be replaced with HRIS. Moreover, HRIS provides the immediate access to the required information in an original form which promotes a common culture of sharing and updating employee's personal information among them. HR mangers can inform the employees about company updated information more easily. It also supports the employees to deal with HR related activities that emerged from their own positions. Besides, HRIS supports employers to get regular information about what employees have already been achieved which enables them to design their career plan by providing the future demand. As employees of the sample industry almost highly educated, they will be able to manage this type of technological revolution in the field of HRM. Moreover, to get the benefits from HRIS to full extent, organizations should ensure suitable employee training facilities. In addition, senior management should come forward with positive attitude to institutionalize the concept of HRIS in business organizations. However, findings of the study will strengthen the existing literature on the perceived importance of HRIS irrespective of demographic characteristics of HR end-users. Similarly, the study results may enrich the knowledge of HR professionals to better understand about the importance of HRIS and emphasize on its effective implementation. It may also provide better platform for future researchers for further study across the countries on the importance of HRIS to the firm's performance.

\section{Recommendation for Future Research}

This study is limited to examine the importance of using HRIS in business organizations. Since, this technology is comparatively new in the business environment in Bangladesh, vast scopes are lagging behind to bring into peoples' insights. The same type of research with the identical title may be conducted onto more than one industry across many countries. Further study should be needed to explore the impact of HRIS on the firm's overall performance. As most of the researches highlight the administrative role of HRIS, an attempt to explore whether HRIS has any linked to the strategic role of HRM may add new dimension in this field. As this technology supports HR professionals to become more efficient in dealing organization valuable human resources, one can examine whether HRIS enables the HR end-users to build future leaders in the organization or not.

\section{References}

[1] Liang, T.P., You, J.J. and Liu, C.C. (2010) Resource-Based Perspective on Information Technology and Firm Performance: A Meta Analysis. Industrial Management \& Data Systems, 110, 1138-1158. http://dx.doi.org/10.1108/02635571011077807

[2] Harris, T.E. and Nelson, M.D. (2008) Applied Organizational Communication: Theory and Practice in a Global Environment. Taylor \& Francis Group, New York.

[3] Ruel, H., Bondarouk, T. and Looise, J.K. (2004) E-HRM Innovation or Irritation: An Empirical Study in Large Five Companies on Web-Based HRM. Management Review, 15, 364-380.

[4] Batool, S.Q., Sajid, D.M.A. and Raza, D.S.H. (2012) Benefits and Barriers of Human Resource Information System in Accounts Office \& Azad Jammu \& Kashmir Community Development Program. International Journal of Humanities 
and Social Science, 2, 211-217.

[5] Troshani, I., Jerram, C. and Hill, S.R. (2011) Exploring the Public Sector Adoption of HRIS. Industrial Management \& Data Systems, 111, 470-488. http://dx.doi.org/10.1108/02635571111118314

[6] Wiblen, S., Dery, K. and Grant, D. (2010) Transitioning from a Proprietory to Vanilla HRIS: The Resulting Implications for Talent. The 3rd European Academic workshop on Electronic Human Resource Management, Bamberg, 20-21 May 2010, 326-341.

[7] Cappelli, P. (2001) Making the Most of On-Line Recruiting. Harvard Business Review, 79, 139-146.

[8] Feldman, D.C. and Klaas, B.S. (2002) Internet Job Hunting: A Field Study of Applicant Experiences with On-Line Recruiting. Human Resource Management, 41, 175-192. http://dx.doi.org/10.1002/hrm.10030

[9] Gasco, J.L., Llopis, J.A. and Gonzalez, M.R. (2004) The Use of Information Technology in Training Human Resources: An E-Learning Case Study. Journal of European Industrial Training, 28, 370-382.

[10] Hoobler, J.M. (2004) An Analysis of Current Human Resource Management Publications. Personnel Review, 33, 665676.

[11] Ruel, H., Bondarouk, T. and Looise, J.K. (2004) E-HRM: Innovation or Irritation: An Explorative Empirical Study in Five Large Companies on Web Based HRM. Management Review, 15, 364-380.

[12] Burbach, R.A. and Dundon, T. (2005) The Strategic Potential of Human Resource Information Systems: Evidence from the Republic of Ireland. Intentional Employment Relations Review, 11, 97-117.

[13] Lengnik-Hall, M.L. and Moritz, S. (2003) The Impact of e-HR on the Human Resource Management Function. Journal of Labor Research, 24, 365-379. http://dx.doi.org/10.1007/s12122-003-1001-6

[14] Hendrickson, A.R. (2003) Human Resource Information Systems: Backbone Technology of Contemporary Human Resources. Journal of Labor Research, 24, 382-394. http://dx.doi.org/10.1007/s12122-003-1002-5

[15] Sadiq, U., Khan, A.F. and Ikhlaq, K. (2012) The Impact of Information Systems on the Performance of Human Resources Department. Journal of Business Studies Quarterly, 3, 77-91.

[16] Chugh, R. (2014) Role of Human Resource Information Systems in an Educational Organization. Journal of Advanced Management Science, 2, 149-153. http://dx.doi.org/10.12720/joams.2.2.149-153

[17] Adamson, L. and Zampetti, R. (2001) Web-Based Manager Self-Service: Adding Value to the Work. In: Walker, A., Ed., Web-Based Human Resources, McGraw-Hill, New York, 24-35.

[18] Sharyn, D., Gardner, D.P.L. and Bartolc, K.M. (2003) Virtual HR: The Impact of Information Technology on the Human Resource Professional. Journal of Vocational Behavior, 63, 159-179.

[19] Kovach, K.A. and Cathcart, C.E. (1999) Human Resource Information Systems (HRIS): Providing Business with Rapid Data Access, Information Exchange and Strategic Advantage. Public Personnel Management, 28, 275-282. http://dx.doi.org/10.1177/009102609902800208

[20] Bal, Y., Bozkurt, S. and Ertemsir, E. (2012) The Importance of Using Human Resources Information Systems (HRIS) and a Research on Determining the Success of HRIS. Proceedings of the International Conference on Management, Knowledge and Learning, Celje, 20-22 June 2012, 53-62.

[21] Teo, T.S.H., Lim, G.S. and Fedric, S.A. (2007) The Adoption and Diffusion of Human Resource Information Systems in Singapore. Asia Pacific Journal of Human Resources, 45, 44-62. http://dx.doi.org/10.1177/1038411107075402

[22] Kwon, T.H. and Zmud, R.W. (1987) Unifying the Fragmented Models of Information System’ Implementation. Critical Issues in Information System Research, 227-251.

[23] Bangladesh Bank (2013) Annual Report. Appendix-3, 27.

[24] Tabachnick, B.G. and Fidel, L.S., Eds. (2007) Using Multivariate Statistics. 5th Edition, Pearson Education, Boston.

[25] Kaiser, H. (1974) An Index of Factorial Simplicity. Psychometrika, 39, 31-36. http://dx.doi.org/10.1007/BF02291575

[26] Bartlett, M.S. (1954) A Note on the Multiplying Factors for Various Chi Square Approximations. Journal of the Royal Statistical Society, 16, 296-298.

[27] Sekeran, U., Ed. (1992) Research Method for Business: A Skill Building Method. 2nd Edition, John Wiley and Sons Incorporation, USA.

[28] Ngai, E.W.T., Chuck, C.H.L., Simon, C.H.C. and Francis, K.T.W. (2008) Importance of the Internet to Human Resource Practitioners in Hong Kong. Personnel Review, 37, 66-84. http://dx.doi.org/10.1108/00483480810839978 